\title{
On Ancient Chinese Classical Linguistics
}

\author{
${\text { Li Kai* }{ }^{*} \quad \text { Huang Weifeng** }}^{* *}$
}

\begin{abstract}
This paper explores some problems concerning ancient Chinese classical linguistics. It is maintained that there are both similarities and obvious differences between it and western philology. The development of ancient Chinese linguistics from the Pre-Qin Period to the Qing Dynasty can be divided into five stages: the embryonic stage, the stage for laying the foundation, the preparatory stage, the stage of growth, and the stage of overall revival and prosperity. The literature produced during this period can be grouped in six categories: gloss exegesis, orthographical form and meaning, phonological form and meaning, historical phonology, grammar on function words, and rhetoric. It is pointed out that, in researching the theoretical history of ancient Chinese linguistics, great importance should be attached to the consistency between history and theoretical logic, cultural background as reference, and textual research methodology.
\end{abstract}

Key Words: ancient Chinese classical linguistics, stages, classification, historical methods

\section{The nature of literature linguistics}

Was there linguistics in ancient China? The answer is affirmative. There were different branches of linguistics in ancient China, such as phonology, Cang Ya Xue (仓雅学) ${ }^{\mathbb{1}}$, exegesis, philology, grammar on function words, rhetoric and so on. In the Pre-Qin Period, there were systematic theories concerning language and philosophy. All this can prove that linguistics did exist in ancient China. Compared with western philology, there are both similarities and obvious differences.

\subsection{Similarities}

What are the differences between linguistics and philology? Generally speaking, in terms of object of study, linguistics deals with natural language, including its sound, meaning and

\footnotetext{
${ }^{*}$ Li Kai: Department of Chinese and Literature, Nanjing University, Nanjing 210093, Jiangsu, China. E-mail: likai43@yahoo.com.cn.

** Huang Weifeng: School of English and International Studies, Beijing Foreign Studies University. E-mail: wfhuang1970@yahoo.com.cn.

(1) Cang Ya Xue literally means "a study of Cang Ya". Cang comes from the initial character of the book name Cang Jie Pian, and Ya the character of the book name Er Ya. The former is a reader written in the Qin and Han Dynasties, while the latter, created in the Pre-Qin Period, is the first Chinese dictionary based on meaning. This study dates from the Han Dynasty and until the Qing Dynasty, a lot of works were written to interpret Er Ya, thus developing the so-called Ya Xue (a study of Er Ya).
} 


\section{Li Kai Huang Weifeng}

grammar, while philology is concerned with written language and its conclusions are not systematic. Originally, the term philology, whose Chinese translation is Yu Wen Xue, refers to the study of classical Greek and Latin. Etymologically, just as philosophy means the love of wisdom, so philology is the love of words which are used as an instrument to record a language. Therefore, it is reasonable to restrict the coverage of philology to written language. Written language is different from the oral language of the same period in that the former is artificial and only approximate to the latter. Due to the temporal and spatial changes in history, a lot of research needs to be done into such an artificial language.

In terms of research methodology, both induction and deduction are necessary. Philology is to generalize some rules about and trace the sources of the written language, characters and literature. In annotation, modern characters should be used to explain ancient ones; in the search for literature, we should track down the origin. For example, in the study of the system of Chinese characters as a recording instrument, there are certain prescriptive patterns to be followed in the investigation into original and contextual meanings of a character and in the use of quotations from literature as evidence of annotations. But linguistics is the extension of the non-finite patterns of the internal structure of language. For instance, lexicology is to explore the formative rules in the lexical system; semantics may be used to find out the semantic clusters and hierarchy; phonetics is to identify distinctive features; in grammatical research, rules should be generalized from individual expressions; within a particular language system, the various grammatical rules are to serve the expression of meaning; one grammatical feature often governs several semantic aspects, and so on. In a word, in terms of methods, induction, analogy, combination of forms, deduction, and even systematic investigation are all necessary in linguistics.

From the relevant works listed in Section 3, it can be seen clearly that ancient Chinese linguistics has some features in common with philology.

Of course, philology is still connected with linguistics. There are a lot of things in common between them in terms of deep logic and ultimate logical directions. Thus, they can be examined based on the same research system and within the same framework of theoretical history. Logically, there is no clear-cut boundary between induction and deduction, especially in terms of reasoning. Gorsky (1960:266) holds that thorough inductive reasoning is a typical kind of deduction. There is something similar between philology and linguistics in research approaches. Induction is applicable to both of them, and induction in philology is a special kind of deduction in linguistics. In ultimate logical directions, both of them can be reduced to semantics. If philology can be compared to elementary mathematics, then linguistics can be regarded as higher mathematics. They are different in scientific levels, the former being included in the latter. That is also the reason why the achievements in philology can be further pushed forward in linguistics. 


\section{On Ancient Chinese Classical Linguistics}

\subsection{Differences}

Ancient Chinese linguistics is also different from western philology in many aspects. Based on ancient Chinese, it can be seen that Jia Gu Wen (inscriptions on bones or tortoise shells in the Shang Dynasty), Jin Wen (inscriptions on ancient bronze wares) and the written language of Chun Qiu (the Spring and Autumn Period) and Zhan Guo (the Warring States Period) are very close to the spoken language in the North of China. Mr. Hong Cheng (2000:98) points out that the written language of Xi Zhou (Western Zhou Dynasty, 1046-771 B.C) corresponds almost exactly to the oral language and that, in the description of language in the Yin Dynasty, the type called Shang Shu (尚书) in the book Shang Shu (商书) is indispensable. From this point of view, Chinese philology based on ancient written Chinese is actually a study of the oral language of that time and thus can be regarded as a sort of linguistics without doubt.

Ancient Chinese linguistics places a great emphasis on the study of meaning. American linguist E.Sapir mentions Chinese at least twenty times in his book On Language: An Introduction to the Study of Speech. In this book, he describes Chinese as "soberly logical", implying that Chinese is transparent and logical in the expression of meaning, and he maintains that Chinese grammatical rules are permeated with semantic features due to the lack of regular inflections. For example, the complement in ancient Chinese is implied in the meaning of a verb; even function words can be explained semantically; the grammatical rules are listed based on meaningful analysis; an interpretation of tense, mood or person depends only on semantic categories, and sometimes such an interpretation is equally effective either semantically or grammatically; the semantic materials used come from ancient literature. Because of this, Sapir even complains that westerners are indifferent towards sober logic in Chinese and maintains that Chinese words and phrases are a sort of spiritual essence of foreign technology. For another example, in Chinese research, much attention is paid to its characters which can serve as not only a recorder of language but also a carrier of rich information. In a word, in Chinese research, emphasis is placed on collection of annotations of words, classification of meanings, anatomical analysis of the form of characters, arrangement based on semantic order, and a semantic comparison with numerous quotations from ancient literature, etc.

In ancient Chinese literatures, philology and linguistics often intertwined. Take the well-known book entitled Shuo Wen Jie Zi Duan Zhu (说文解字段注, Duan Yucai's annotation of Shuo Wen Jie $\mathrm{Zi}$ ) as an example. Based on meaning, Duan Yucai, the annotator, traced every character in Shuo Wen Jie Zi (an etymological dictionary) back to its source in ancient literatures, including the materials about both lexicon and written language. Such an approach can be considered as textual evidence in a broad sense. In this way, the entries in the dictionary become very vivid. No doubt, such a practice belongs to 


\section{Li Kai Huang Weifeng}

philology. As all the characters are explained through concrete examples, most of the entries based on characters in the original version are actually converted into those based on words in the annotated version. Besides, the Chinese words consisting of two or more characters in the original dictionary are marked with the character dòu (逗) when used in annotations, such as zhé ráng (磔禳, meaning "split the livestock for the memorial service for ancestors") under the radical “SHI" (示), jǐn yú (瑾瑜, meaning "beautiful jade") and shān hú (珊瑚, meaning “coral”) under the radical “YU”(玉), and $z h \bar{u} y u$ (茱英, meaning "cornel, a small deciduous tree") under the radical “CAO"(屾). In addition, in the dictionary, there are already semantic categories and hierarchical arrangement of meaning based on the principle of joining characters according to form. Duan made a further explanation of the grouping of semantic categories. For example, about radical YU (玉, meaning jade), he said, "Under the heading of liáo (璙), all of the characters are the names of jade wares. zàn (瓒) refers to jade' grade, and ying (瑛) the luster. The five characters under the heading of wú (璑) describe the beauty or ugliness of jade objects... And 灵(ling) is the magician who is good at using jades." In conclusion, he regards such a practice as the logic of Shuo Wen Jie Zi and the order of such logic as the basis of philology. Undoubtedly, Duan's research belongs to linguistics and is a valuable attempt to explore the rules concerning meaning, semantic clusters and semantic hierarchy within the Chinese vocabulary. Besides, he contributes greatly to linguistics in other aspects, such as the discrimination between synonyms, research on extended meaning and phonetic loan characters (characters used to represent homophones), the interpretation of Liu Shu (the six categories of Chinese characters, including self-explanatory characters, pictographs, pictophonetic characters, associative compounds, mutually explanatory characters and phonetic loan characters), as well as the examination of the relationship between components and meaning of Chinese characters.

Duan also collated the different versions of Shuo Wen Jie $\mathrm{Zi}$ based on semantic categories and levels. For instance, in the modern version entitled The Radical "YU" in Shuo Wen Jie Zi by Xu Xuan, jiăo (璬), héng (珐) and jué (玦) are placed after mào (瑁) and before rui (瑞), while in Xu Kai's version, héng (珩) and jué (玦) are put at the end of this radical. But according to Duan, both arrangements are not in accordance with the original order of the dictionary. Based on the fact that the nine characters from jiăo (璬) to zhăo (瑵) form a cluster under the semantic feature of decoration, the three characters of jiăo (璬), héng (㹸) and jué (玦) should be put after rui (瑞) and before ěr (珥), thus forming a cluster together with characters from ěr (珥) to zhăo (瑵). He even identified some mistakes in ancient books. For example, based on the meaning of gān (貋), he pointed out that the character hàn (捍) in the sentence “捍珠以纳其间” (meaning "put beautiful pearls there") from Xin Shu (new book) by Jia Yi should be changed to gān (貋). 


\section{On Ancient Chinese Classical Linguistics}

Sometimes he even corrected Xu Shen's mistakes. For instance, in the original dictionary Shuo Wen Jie Zi, it is said that fên (氛) and fên (雾) belong to the same entry and that fên (氛) may also take the radical YU (雨). Such an explanation is inappropriate in terms of either meaning or style. Based on meaning and semantic categories, Duan pointed out that fèn (雾) and fên (氛, meaning “auspicious atmosphere") refer to different things and should not be mixed up.

All such practices belong to philology based on textual research, so it can be seen that philology and linguistics intertwine in Duan's annotations and sometimes it is indeed very difficult to draw a clear line between them.

Whether such research is systematic depends to a large extent on the quantity and evaluation of the relevant achievements. Some works do not seem to be systematic, but an in-depth analysis will show their systematic nature and consistency. Take the book entitled Er Ya (尔雅, an ancient Chinese book containing commentaries on classics, names, etc.) as an example. Indeed, at first glance, it seems to be an index of difficult words. But with an analysis of the methods of definition, we can identify the following four ways: the mutual annotation method based on relations in consonants and vowels, including the use of modern words for old words, standard for dialect, and elegant for vulgar or vice versa; annotation by means of synonyms which are not related in terms of consonants or vowels; the description of semantic boundaries; and annotation based on sound. Moreover, these methods have their respective features. For example, the description of semantic boundaries is characterized by the use of numbers, affirmative sentence type, the logical pattern of attribute + genus, and the Chinese character $z h \bar{l}$ (之) to form a kind of grammatical relationship similar to the one between numerator and denominator in a fraction. Similarly, the annotation method based on phonetics can also be further analyzed in this way. Thus, it is clear that the potential rules can be revealed only after an in-depth investigation is made into the original work Take Guo Pu's annotation of Fang Yan (方言, meaning "dialect") as another instance. In the annotation, the so-called method "Fan Qie" is used. ${ }^{2}$ However, by comparing the category of Chinese words sharing the same final in the annotation established by means of joining some characters according to form with those used in the book entitled Guang Yun (广韵), it can be seen that Guo's annotation is a record of the historical changes in phonetics from ancient times to mid-ancient and that some rules can be generalized, about the sounds or approximate ones used in these periods.

\footnotetext{
(2) Fan Qie (反切) is a traditional method of indicating the pronunciation of a Chinese character by using two other Chinese characters, the first having the same consonant as the given character and the second having the same vowel (with or without final nasal) and tone. For example, the pronunciation of 同 (tong) is indicated as 徒 (tu)红 (hong) 切, meaning a combination of the consonant $t$ from 徒 (tu) and the vowel plus nasal ong from 红 (hong).
} 


\section{Li Kai Huang Weifeng}

In fact, systematic theories are absent not only in such famous Chinese linguistic works as Er Ya, Shuo Wen Jie Zi and Shi Ming (释名), and the works based on substantial evidence written after the Pre-Qin Period, but also in the famous ten Chinese classic works on astronomy and mathematics represented by Zhoubi Suanjing (written in the first century BC during the Western Han Dynasty), most of which are only a collection of calculating questions and are thus called "arithmetic". Even in the works of the Ming Dynasty such as Bencao Gangmu (compendium of materia medica) and Tiangong Kaiwu (exploitation of the works of nature), there is no systematic discussion of theories but only factual statements. This phenomenon has something to do with the prevalence of thoughts of the Confucian school after the Han Dynasty. The Confucian school maintains that one should only elaborate on other's theories without stating any of one's own views, and the Taoist school believes in not-being, holding that being comes from not-being. Therefore, a popular rhetorical saying goes that one should show people only the embroidered mandarin duck without letting them know the process. Such is the case in ancient Chinese linguistic works. Although the "embroidered process" is not made clear in such linguistic works, we cannot conclude that no systematic theories have ever been developed. Instead, it is our duty to discover and develop them into a history.

Based on the above analysis, it can be seen that the term "classical linguistics" put forward by Lù Zōngdá (1980:7, 11) is appropriate for the description of ancient Chinese linguistics.

\section{Periods of development}

Ancient Chinese linguistics can be said to begin in the Pre-Qin Period and come to an end with the book entitled Mashi Wentong (马氏文通) in 1898. This book marks the beginning of a new period in the history of Chinese linguistics with the introduction of western linguistics, known as the modern and contemporary period.

A reasonable division of the periods will not only provide a basic framework for the study of such linguistics, but also help to prevent the misunderstanding of the history of linguistics as an index of editions, illustrations, commentaries and sources of a certain book, or the solution to a problem. Thus, we will be able to cover the various aspects of linguistics, such as the cultural background on which the development of different linguistic doctrines depend, famous linguists, the intrinsic historical relationship between works, the evolution of linguistic doctrines, academic approaches, their influence, and so on. The history of linguistics is an investigation into theories, so the demarcation between it and the history of language (including sound, vocabulary and grammar) is clear-cut. Just like literary and scientific works, linguistic achievements in history are regarded as a crystallization of beauty and wisdom, for they represent a language as an object according 


\section{On Ancient Chinese Classical Linguistics}

to the intrinsic logic and structure of linguistics and reflect people's perceptions about language and the process of research. So linguistics is an integration of object and subject, not just a study of the history of pure language.

Ancient Chinese people understood their language from different perspectives. In the Pre-Qin Period, linguistics was included in the philosophers' discussions about philosophy and logic, and in some cases linguistics was touched upon directly. For example, in the logic of Mohism, a lot of ideas about language are included. In Mo Jing (墨经, the technological volumes of Mo $\mathrm{Zi}$, completed in the period from the $5^{\text {th }}$ to thr $4^{\text {th }}$ century $\mathrm{BC}$ ), there is one volume about language called Yujing (语经), and a classification system based on ten kinds of sameness and three kinds of difference, which contain some general statements about the methods to categorize concepts and words. In Xunzi's theory about the rectification of names, the conventional relationship between names and their referents are directly discussed. Besides, there are clear statements about the establishment of a common national language and the promotion of the official language used in this period. The powerful and smooth essays in Mengzi (Mencius) are excellent examples of the rhetoric based on deduction and analogy without categorization.

All of these philosophical and linguistic ideas have exerted a great influence upon the future generations. For example, in Jiuzhang Suanshu (nine chapters on mathematical art, one of China's early writings on mathematics completed in the first century), names in a language are considered symbols, which is obviously a further development of Xunzi's

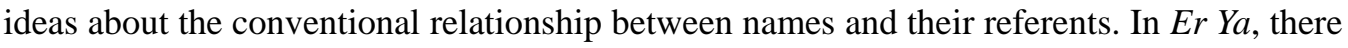
are nineteen semantic categories with subcategories under each, thus showing a hierarchy. Different semantic levels are provided even in the explanation of the same word. Such practice follows the two general logical principles about language discussed in Mo Jing, i.e., analogy based on order, and deduction and analogy based on similarities and differences. In Shuo Wen Jie Zi, the characters under the same radical are arranged based on their semantic categories to avoid confusion. Regarding the classification of radicals, Xu Shen said that, just as all the things were grouped in different categories, so a total of 133441 characters were arranged according to their radicals, thus avoiding confusion. The ideas and methods in Shuo Wen Jie Zi Xu (说文解字叙) can be traced to Yi Jing (易经). In the section entitled Xi Ci (系辞) of Yi Jing, Confucius said, "What do people think about the world? In the world, there are different roads leading to the same destination and different ideas resulting in the same conclusion." In the annotation, Han Kangbo said, "To get the main points, it's not necessary for you to do extensive reading. Through some common logic, you will obtain the knowledge without much thinking." In terms of ideology and method, the inductive logic of the Pre-Qin Period is applied in the analysis of semantic categories and their classification in $\mathrm{Er} \mathrm{Ya}$, and the analysis of radicals and the joining of characters 


\section{Li Kai Huang Weifeng}

according to form in Shuo Wen Jie Zi. So the connection between the two books is very obvious. In a profound sense, both books are based on some common patterns so as to avoid confusion. In a word, it may be said that the connections between Shuo Wen Jie Zi and $E r Y a$ are various, for both of them are reflections of language as an object. It is widely recognized that Fáng Yán will become Er Ya with many of the entries about the names of places in its first volume Shi Gu (释诂) and second volume Shi Yan (释言) eliminated. Cang Ya Xue originates from $\mathrm{Er} \mathrm{Ya}$, with its methods for gloss mainly based on $\mathrm{Er} \mathrm{Ya}$ and Shuo Wen Jie Zi. All of these examples show that the dictionaries and the works about form and sound of Chinese characters are not unrelated with each other. Instead, there is a certain intrinsic historical or logical connection between them, which is sometimes obvious and sometimes hidden. Chinese Linguistics indeed has its own history. It is clear that no investigation can be made into the historical connection between the various works in terms of content if ancient Chinese linguistics is regarded only as a sort of philology based on individual explanations instead of as part of Chinese linguistics in general. For the same reason, it is neither possible nor necessary to undertake a profound research on various dictionaries and books about sound, especially from the point of view of modern linguistics. Therefore, it can be seen that the difference between linguistics and philology involves not only name, but also a series of serious questions, such as research methodology, the evaluation of cultural heritage, the discovery of intrinsic connections and even the use of the heritage to serve modern sciences.

Based on linguists, linguistic ideas and relevant works, and with society and history as references, ancient Chinese linguistics can be divided into the following five periods: (1) the Pre-Qin period, known as the embryonic stage; (2) the Two Hans (Western and Eastern Han Dynasties) based on gloss exegesis, during which the foundation way laid; (3) the period ranging from the Wei and Jin Dynasties to the Northern and Southern Dynasties, known as the preparatory stage for the research on speech sound; (4) the period including the Tang, Song, Yuan and Ming Dynasties, in which research is focused on speech sound; (5) the Qing Dynasty, known as the general revival and prosperity of ancient Chinese linguistics.

Within the above periods, research can be done on the various aspects of Chinese linguistics, including general linguistic theory, characters, phonology, exegesis, dictionary, rhetoric, and research methodology, with linguistic history as the logical backbone. For example, historical and logical researches can be done on various linguistic theories in the Pre-Qin Period, such as Confucius' ideas about speech; Mencius's thoughts about the relationship between speech, thinking and deep mind; the ideas about the rectification of names and incomparability between different kinds in Mo Jing; classification in Er Ya; ontology about name in $\mathrm{Lao} \mathrm{Zi}$ (founder of Taoism); Zhuang Zi's sayings that words cannot 


\section{On Ancient Chinese Classical Linguistics}

express all one intends to say and that one's ideas may not equal one's objects. In view of the significant influence of the monism about $Q i$ (for vitality) of the Pre-Qin Period upon later rhetoric and writing, as well as the connection between this philosophical and aesthetic theory and the contemporary philosophical linguistics, some research should be done on Wen Xin Diao Long (文心雕龙) and Wen Ze (文则) based on the above historical framework.

It is thought that the above division will break away from the traditional research methodology and reveal the historical transitions and the hierarchy of the various parts of ancient Chinese linguistics, thus establishing a system composed of a long series and characterized by hierarchical transitions. Without doubt, such a systematic research will exert a far-reaching influence on the development of theories about modern Chinese linguistics, grammar and vocabulary. It can even benefit the research on ancient Chinese logic and methodological history.

\section{Classification}

In terms of Chinese classical linguistics, there are a large number of relevant works, which belong to various types. In Si Ku Quan Shu Zong $M u$ (四库全书总目, a catalogue of Si Ku Quan Shu), works concerning Chinese language and characters are listed in the category of Xiao Xue (philological studies) under the division of classics. This category can be further divided into the following three kinds: gloss under $\mathrm{Er} \mathrm{Ya}$, dictionaries under Shuo Wen Jie Zi and rhyme books under Guang Yun. In this way, the following subtypes can be obtained:

A. Gloss, including books which base explanation on semantic categories, represented by Er Ya; books on common sayings and dialects in ancient and modern societies, represented by Fang Yan (dialect); books which explain the meaning of words based on sound, such as Shì Ming (释名); books on proverbs and common sayings, such as $\mathrm{Su} \mathrm{Yu}$ (俗 语) by Yang Shen in the Ming Dynasty; books which examine the name and description of a thing, such as $\mathrm{Er} \mathrm{Ya} \mathrm{Yi} \mathrm{by} \mathrm{Luo} \mathrm{Yuan} \mathrm{in} \mathrm{the} \mathrm{Song} \mathrm{Dynasty;} \mathrm{collections} \mathrm{of} \mathrm{ancient} \mathrm{gloss,}$ such as Jing Ji Zuan Gu (经籍纂诂).

B. Works on meaning and orthographical form of Chinese characters, including collections of words in common use, such as Ji Jiu Pian (急就篇); dictionaries based on radicals, such as Shuo Wen Jie Zi; books on Shuo Wen Jie Zi and related works, such as Shuo Wen Jie Zi Xi Zhuan (说文解字系传) and Shuo Wen Jie Zi Zhu (说文解字注); books on the classification of Liu Shu (六书) and the discrimination of the form of a written character, such as Liu Shu Lue (六书略) by Zheng Qiao in the Song Dynasty; orthographical dictionaries and collections of different calligraphic styles of characters, 


\section{Li Kai Huang Weifeng}

such as Gan Lu Zi Shu (干禄字书); textual explanations of ancient characters, such as Han Jian (汗简) by Guo Zhongshu in the Song Dynasty; books on the writings of an ancient or contemporary writer that are not in current circulation, such as Zi Lin Kao Yi (字林考逸).

C. Works on phonological form and meaning, including books on classics and history, such as Jing Dian Shi Wen (经典释文); books on the discrimination of sound and meaning, such as Qun Jing Yin Bian (群经音辨); books on sound and meaning of Buddhist classics, such as Yi Qie Jing Yin Yi (一切经音义); textual criticisms of various kinds, such as Kuang Miu Zheng Su (匡谬正俗).

D. Historical rhymes, including rhyme books in different dynasties, such as Qie Yun (切 韵) and Guang Yun (广韵); rhyme pictures and books on rhymes based on four grades, such as Yun Jing (韵镜); textual research on ancient sounds, such as Mao Shi Gu Yin Kao (毛诗古音考).

E. Books on functional words and grammar, such as Zhu Zi Bian Lue (助字辨略) and Jing Chuan Shi Ci (经传释词).

F. Rhetorical works, including books that go into particulars of rhetorical examples, such as $G u$ Shu Yi Yi Ju Li (古书疑义举例), and books on rhetorical theories, such as relevant chapters in Wen Xin Diao Long and Wen Ze.

The above classification is based on the content of works, but several kinds of books are grouped together because of their internal logical relationship, so the classification is also based on logic. Obviously, the books grouped based on logical classification should belong to different historical periods. Apparently, unity can be achieved in the former classification, while confusion may result in the latter. But, as a matter of fact, this is not the case. An interpretation based on historical periods is not a sort of philological chronicle. Instead, as mentioned above, the span of different linguistic periods is rather long, and therefore numerous books of the same kind can be included. In addition, a study of linguistic history should include an exploration into the linguistic ideas of the writers of influential works. Providing annotations for ancient works is a way to create books, thus resulting in numerous interpretations and developments. But they should be distinguished from the original works. For example, in the Warring States period (475-221 B.C), there was Er Ya, and in the Qing Dynasty, there was Er Ya Yi Shu (尔雅义疏). Thus, in the study of Er Ya, Er Ya Yi Shu can be used as a reference, and in the Qing Dynasty, it can be studied as a noumenon. Such a practice would not cause either break or confusion. So is the relationship between Shuo Wen Jie Zi and Duan's annotations. It is improper to confuse the works in different historical periods and deny the unique achievements made in later periods just because of their common source. On the other hand, the existence of original works and later achievements cannot be considered a kind of "isolation". Similarly, it is quite natural to evaluate the present achievements based on ancient linguistic works. As is 


\section{On Ancient Chinese Classical Linguistics}

well known, a logical study of an individual object can be undertaken in different levels and from various angles, with a consideration of both the past and the present. Such a study should be open instead of closed. Only a deep logical analysis of an individual object in different levels can better reveal the historical connections between different objects.

\section{Historical approach}

The research on the theoretical history of Chinese linguistics must be based on relevant works. In terms of methodology, the following aspects are obtained:

\subsection{Consistency between history and logic}

In the study of ancient Chinese linguistics, there should be consistency between the development of academic history and scientific logic, and consistency between historical analysis and logical analysis must be adopted as a general guidance. As the basis of Cang Ya Xue and philology respectively, Er Ya and Shuo Wen Jie Zi are connected with each other both logically and historically.

Characters and the explanation of their meanings cannot be separated. Semantic evidence is not as powerful as phonological evidence. Therefore, search for consistency between sound, spelling and meaning becomes the starting point and the basic method in the study of the features of Chinese characters. Sound-annotation has a long history. It can be found in Yi Jing (易经, the book of changes), which says, “需 (requirement) is 须 (necessity), both of which have the same pronunciation Xu." In the book entitled Shi Ming (explanation of names) of the Han Dynasty, the connection between sound and meaning is so widely recognized that this relationship is no longer limited to a root and its derivatives. The intrinsic relationship between sound and meaning or between a name and its referent is thought to exist everywhere, which is a violation of the conventional theory put forward by Xunzi. Nevertheless, the discussions on roots and their derivatives in the book are generally valid. Such ideas have a great influence on the theory of You Wen in the Song Dynasty, according to which the sound on the right side of a Chinese character determines its meaning. Such an influence can also be traced to the research on a character's root and a word's root in the Qing Dynasty, as can be seen in Wen Shi (文始) by Zhang Binglin. The principle that there is a close relationship between sound and meaning was widely used in exegesis. Based on this principle, the relationship between sound and meaning within a single Chinese character was established, which further led to the systematic development. In Liushu Yinyun Biao (六书音韵表, A Table of Rhymes for Liushu), Duan Yucai grouped the ancient rhymes in 17 categories. Such a scientific system formed the basis of the book, making the seemingly independent annotations a unified whole, hence the source of sound and meaning of a character. As mentioned above, Duan's work contains a lot of ideas about lexicology; especially the 17 categories of rhymes put forward by him become the central 


\section{Li Kai Huang Weifeng}

clue for the explanation of the meaning of Chinese words.

This principle of consistency between history and logic should be followed in the study of any work. Take Guang Yun as an example. It is the product of the various achievements since the Wei and Jin Dynasties. From the remnants of Qie Yun, it can be seen that Lu Fayan in the Sui Dynasty already identified 193 rhymes, 13 less than the 206 rhymes listed in Guang Yun. After that, a lot of similar works appeared, such as Wang Yun (王韵), Tang Yun (唐韵) and Qie Yun by Li Zhou (李舟《切韵》). Therefore, the appearance of Guang Yun is quite natural.

The internal structure of Guang Yun is like a coordinate, with rhyme classes of level tone as its vertical axle, and the four tones as its cross axle. Besides, there are Chinese characters ending in sounds other than $-m,-n,-n g$ and $-b,-d,-g$, those with $-m$ or $-n$ or $-n g$ as the terminal sound, and the so-called open and close movement. Based on this, together with a consideration of the historical changes in sound and the distinctions between northern and southern dialects, the 206 rhymes are obtained. Thus, the structural system of Guang Yun is not only a synchronic description of the sound at that time, but also a reflection of the historical phonetic changes, even with several rhyme classes for historical record. According to modern textual research, the distinctions between [-ubi] (the classical vowel in Chinese character 灰) and [-pi] (the classical vowel in Chinese character 咍), [-1wan] (the classical vowel in Chinese character 元) and [-uən] (the classical vowel in Chinese character 魂), [-ien] (the classical vowel in Chinese character 先) and [-1عn] ( the classical vowel in Chinese character 仙), [-1əu] ( the classical vowel in Chinese character 尤) and [-əu] ( the classical vowel in Chinese character 侯) ${ }^{3}$ are based on Yun Ji (韵集, a collection of rhymes) of the Western Jin Dynasty. The coordinate framework in Guang Yun contains the principle of Deng Yun Tu (a rhyme picture based on four grades), thus marking the beginning of such an academic branch.

The history of linguistics has proved that logical connections are the basis of historical clues. As a matter of fact, in the past, scholars did a lot of work in this aspect. In the Song and Yuan Dynasties, Shuo Wen Jie Zi was mocked as a fragmentary book. Wang Jun wrote a book entitled Shuo Wen Li Shi (说文释例, an explanation with examples), in which he put forward additional characters to show distinctions and, beyond the level of single characters, he joined characters according to form. On this basis, he formulated the rules governing the divergence of Chinese characters, thus showing their historical development. In the Qing Dynasty, scholars checked Er Ya according to Shuo Wen Jie Zi, as can be seen in Er Ya Wen Zi Kao (尔雅文字考, a philological examination of Er Ya) by Dai Zhen who

\footnotetext{
(3) The description of certain Chinese characters' classical pronunciation is based on the information provided in Guo Xiliang (1986).
} 


\section{On Ancient Chinese Classical Linguistics}

understood the two works thoroughly. In Mao Shi Chuan Yi Lei (毛诗传义类) of Shi Mao Shi Chuan Shu (诗毛氏传疏) by Chen Huan, the style is in accordance with that of Er Ya; in the book Shuo Ya (说雅) by Zhu Junsheng, Shuo Wen Jie Zi is also arranged in the same style. All of these examples provide rich materials for comparison. In the works Shuo Wen Yin Jing Kao (说文引经考), Yin Qun Shu Kao (引群书考), Yin Tong Ren Shuo Kao (引通 人说考), and Yin Fang Yan Kao (引方言考) by Ma Zonghuo, a modern scholar, critical interpretations are made both synchronically and diachronically. Such works are useful for us to make an internal comparison and trace the historical development. For another example, apparently, it is hard to find any other connection between Shuo Wen Jie Zi and Yu Pian (玉篇) except that the latter is a transformation of the radicals in the former. But a deeper investigation shows that historical inheritance can still be found in terms of semantic order and that, in some cases, connections can also be identified. Needless to say, the absorption and historical development of the ideas of the famous linguists should be based on an analysis of their respective doctrines. The Han school of classical philology in Qing is a case in point. Profound research needs to be done as to the adoption of the method in the Song School and the differences in doctrines.

\subsection{Cultural reference}

In a systematic research on the history of linguistics, the influence of cultural factors upon its development must be taken into account. The rise and fall of the study of Confucian classics and the replacement of classical learning based on official scripts in the Han Dynasty with classical learning based on earlier texts led to the emergence of the Han School of classical philology, thus contributing to the development of exegesis during the two Hans. The decline in the classical learning in the Wei and Jin Dynasties marked the end of exegesis, and the juxtaposition of Buddhism, Taoism and Confucianism symbolized the beginning of Chinese linguistics with phonetics as the main trend. As expected, based on the recited passages from scriptures, Shou Wen (守温) created a table of 30 characters representing the initial consonants for the book on phonology with missing pages. In addition, the emergence of a large number of sounds and meanings in Buddhism provided a large field for the study of sound and vocabulary in middle ancient Chinese.

\subsection{Textual research method with substantial evidence from all kinds of books}

As a common practice in exegesis, the textual research method is also used in the research on the history of Chinese linguistics. The essence of exegesis is the examination of the meaning of an ancient word. In ancient times, such a practice is not only a linguistic approach, but also an instrument of reasoning. In the classics of Confucianism, the logic adopted in those of other ancient philosophers is discriminated against. Instead, the practice used in exegesis is used directly as an instrument of reasoning, which can be typically seen in Yi Jing (the book of changes) and Mencius (孟子). As one of the thirteen classics of 


\section{Li Kai Huang Weifeng}

Chinese philosophy and literature, the book Er Ya can be used as a kind of evidence in the critical interpretation of classics in terms of methodology, which can be vividly shown in the following dialogue. In Xiao Bian (小辨) of Da Dai Li Ji (大戴礼记) (from Shi San Jing Zhushu, 十三经注疏), a lord asked, "I want to learn philology and apply it in politics. Ok?" Confucius answered, "No, it is not necessary for you to learn philology, for $\mathrm{Er} \mathrm{Ya}$ is enough." The textual research method based on generalization and analogy, which is used in Pu Xue (down-to-earth learning) of the Qing Dynasty, is also an approach to exegesis. Such a practical scientific approach is very useful in linguistics.

In exegesis, the emphasis is placed on the explanation of meaning. In ancient times, such an annotation is based on evidence from a variety of other books, which is often seen in a cultural typology concerned mainly with meaning. No doubt, such a practice will have a positive influence upon the investigation into linguistics from a historical point of view. One the one hand, it contributes directly to the compilation of materials about linguistic history. On the other hand, it plays an important role in the improvement of research on the development of linguistics from historical and scientific perspectives. But in this method, too much attention is paid to micro-aspects, resulting in the ignorance of the macro-aspects. Therefore, besides this method, some other approaches must be adopted in the study of the history of ancient Chinese linguistics so as to make it a systematic science characterized by multi-levels, multi-dimensions and reasonable transitions between different series, and to reveal its intrinsic connections with other subjects.

\section{Main references}

Gorky, 1960. Logic. [M] Shanghai: Shanghai People's Press.

Guo Xiliang. 1986. The Manual of Classical Pronunciation of Chinese Characters. [M] Beijing: Beijing University Press

Hong Cheng. 2000. A Selection of Articles Written in Luosong Lu. [C] Nanjing: Jiangsu Ancient Books Press.

Lu Zongda. 1980. A Brief Introduction to Exegesis. [M] Beijing: Beijing Press.

Sapier,E. 1921. On Language: An Introduction to the Study of Speech. [M] New York: Harcourt Brace and World. 